\title{
Energy Consumption and Ecological Footprint in the World's Major Suppliers of Crude Oil: Does Difference in Oil Production Status Between Sub- groups Count?
}

Oluwasegun Babatunde Adekoya ( $\sim$ adekoyaob@gmail.com )

Federal University of Agriculture Abeokuta https://orcid.org/0000-0001-7238-6932

Joshua Kolade Olabode

Federal University of Agriculture Abeokuta

\section{Research Article}

Keywords: Energy consumption, Ecological footprint, OPEC, AMG

Posted Date: June 2nd, 2021

DOl: https://doi.org/10.21203/rs.3.rs-480564/v1

License: (1) This work is licensed under a Creative Commons Attribution 4.0 International License.

Read Full License 


\title{
Energy consumption and ecological footprint in the world's major suppliers of crude
} oil: Does difference in oil production status between sub-groups count?

\author{
Oluwasegun B. Adekoyaa, ${ }^{a, *}$, Joshua K. Olabode ${ }^{b, c}$ \\ aDepartment of Economics, Federal University of Agriculture, Abeokuta, Nigeria \\ bDepartment of Agricultural Economics and Farm Management, Federal University of \\ Agriculture, Abeokuta, Nigeria \\ cE-mail address: jkolabs2@gmail.com; Mobile: +2348066433439 \\ *Corresponding author's E-mail: adekoyaob@gmail.com; Mobile: +2348168889097
}

\section{Abstract}

The need to maintain quality environment despite the increasing human activity and pressure on energy resources remains a topical issue in the field of Environmental Economics. However, we observe that the impact of energy consumption on ecological footprint in the Organization of Petroleum Exporting Countries (OPEC) has not received keen attention in the literature. This study thus delves into the nexus for the country group. For a more robust policy bearing, we partition the countries into Middle-East and non-Middle-East members because of their huge energy supply and consumption differences. Summarizing the results, energy consumption increases environmental degradation across all samples. However, despite the Middle-East countries being the highest per capita energy consumers, their energy consumption contributes less to environmental degradation compared to the non-Middle-East 
22 countries. For completeness, we report the long-run country-specific estimates and find

23 that only in Congo is environmental quality enhanced by energy consumption.

24

25 Keywords: Energy consumption; Ecological footprint; OPEC; AMG

26 
28 Without any doubt, a significant part of our world today is still shaped by energy, 29 particularly non-renewable energy. Regardless of the level of development of countries, energy consumption remains a crucial indicator of economic activity in both developed and developing countries, thus driving a significant part of their economic growth

32 processes. Unfortunately, consumption of energy cannot be disconnected from 33 environmental concerns, as it does not guarantee a fair environmental balance. Tran et 34 al. (2019) note that the economy concurrently relies on natural resources at higher 35 development levels, and then releases pollution that directly impairs the natural ecosystem or environment. In another regards, Uddin et al. (2017) disclose that due to

37 the rapid industrial growth over the past two centuries, the global economy has 38 succumbed to significant and unavoidable increase in the demand for energy that led to 39 the trade-off between economic development and environmental effect to be really challenging to deal with as the demand has rather been largely met by non-renewable 41 energy production that causes greenhouse gas emissions. Following the pursuit of high 42 economic growth by most countries therefore, their use of energy for such purpose 43 results in increasing emission of wastes into the environment (Lee and Chang, 2008).

44 Thus, in the face of rising energy consumption need to aid economic growth, the major 45 challenge of humanity seems to be related to the preservation of the global environment 46 (Uddin et al., 2017). In recent years, the environment has found its way into the 47 forefront of modern contemporary concerns and has thus come under serious policy 
48 designs. This is because of the greenhouse gases accumulated in the atmosphere which 49 then advance climate change. Based on this, there is increasing national and 50 international policies, including the noble Sustainable Development Goals (SDGs) and 51 Kyoto Protocols, on the ways to mitigate environmental degradation and reduce 52 pressure on environmental resources. In fact, among other noteworthy goals, the 53 reduction of pressure on ecological resources and maintenance of conducive and safe 54 environment is at the heart of the SDGs scheme (Nunan, 2015).

55 In view of the need to address environmental concerns, the literature is alarmingly 56 witnessing a plethora of studies on energy consumption-environmental nexus, with 57 mixed findings following. However, it remains yet a weakness of most of these past 58 studies to use carbon emissions as an indicator of environmental degradation 59 (Wackernagel and Rees, 1996), as it only accounts for a minute part of the overall 60 environmental impairment induced by higher energy consumption (Al-Mulali et al., 61 2015a). Thus, recent years have witnessed the expansion of environmental degradation 62 base for empirical analyses by using ecological footprint as a more representative 63 indicator. Apart from acting as an all-inclusive indicator of anthropogenic pressure on 64 the environment (see Kassouri and Altintas, 2020; Vackar, 2012; York et al., 2009), 65 ecological footprint provides insights into the actual ecological biocapacity budget, as 66 well as the degree of the impact of human activities (production, consumption and 67 investment) on environment's regenerative strength (see Vanham et al., 2019; Galli et 68 al., 2020). 
69 The main goal of this study therefore is to examine the energy consumption-ecological 70 footprint nexus in the Organization of Petroleum Exporting Countries (OPEC). We 71 observe that despite the assessment of this nexus for a number of economic groups, 72 nothing is known about the OPEC which constitutes the world's largest producers of

73 crude oil. Apart from being significant producers of the said commodity, they also 74 significantly consume it and depend on it for the functioning of their economies. 75 Meanwhile, it is noteworthy that crude oil is the world's most traded and most 76 consumed commodity. It also falls in and constitutes the largest share of the non77 renewable energy group which is known as a great source of environmental 78 degradation. In addition to the full sample analysis, we further divide the countries into 79 Middle-East and non-Middle-East groups so that a distinct estimation is done for both. 80 This is because the Middle-East countries account for about one-third of global crude oil 81 exports and over one-sixth of the total OPEC production (see Table 1 for 2018 82 estimates). However, they appear not to be the largest consumers of energy, probably 83 due to their developing statuses and small population sizes. This further informs their 84 huge per capita primary energy consumption compared to other OPEC member 85 countries. It is thus worthwhile to examine if the marginal contribution of their huge 86 per capita energy consumption to environmental degradation is significantly different 87 from other members of the OPEC. In addition to this, we examine if the long-run 88 impacts vary across the member countries since energy consumption and efficiency 89 levels differ. 
Table 1: Crude oil exports and primary energy consumption in the Middle-East

\begin{tabular}{|l|l|l|l|l|l|}
\hline Considered Middle- & $\begin{array}{l}\text { \% of oil exports } \\
\text { Eastern countries }\end{array}$ & $\begin{array}{l}\text { in total world } \\
\text { exports in 2018 }\end{array}$ & $\begin{array}{l}\text { OPEC total } \\
\text { exports in 2018 }\end{array}$ & $\begin{array}{l}\text { primary } \\
\text { energy } \\
\text { consumption in } \\
\text { world total }\end{array}$ & $\begin{array}{l}\text { Per } \\
\text { primary energy } \\
\text { consumption }\end{array}$ \\
\hline Iran & 4.04 & 7.50 & 2.06 & 145.86 \\
\hline Iraq & 8.43 & 15.65 & 0.38 & 57.2 \\
\hline Saudi Arabia & 16.09 & 29.88 & 1.87 & 323.4 \\
\hline United Arab Emirates & 5.01 & 9.31 & 0.81 & 492.3 \\
\hline Total & $\mathbf{3 3 . 5 7}$ & $\mathbf{6 2 . 3 4}$ & $\mathbf{5 . 1 2}$ & \\
\hline
\end{tabular}

91 Source: Exports values are computed by the authors, underlying data from the 2019 OPEC Annual

92 Statistical Bulletin, while energy consumption are from BP Statistical Review.

93 If all the Middle-Eastern countries are to be considered, they accounted for about $41.29 \%$ of globally

94 exported crude oil, and about $76.67 \%$ of OPEC total crude oil exports.

95

96 The structuring of the remainder of this paper is as follows: Section 2 reviews relevant

97 studies, Section 3 describes the data and develops the methodology, Section 4 presents

98 and discusses the estimated results, Section 5 gives the conclusion, and Section 6 draws

99 the policy implications

100

2. Review of the literature

101 As earlier noted in the background to the study, empirical studies on the energy 102 consumption and environmental degradation are increasingly becoming prominent in 
103 the general literature especially in recent times due to the ongoing global drive in 104 ensuring an environment devoid of harmful substances, and the need to mitigate the 105 likely occurrence of climate change. These studies also vary in terms of proxies for 106 environmental degradation, methodologies, countries or economic regions and scope, 107 thus resulting into lack of consensus on the established findings.

108 The oldest consideration in the literature connects energy consumption with carbon 109 emissions, where the latter acts as the proxy for environmental degradation. Al-Mulali 110 (2014) use the Vector Error Correction Model (VECM) and Granger-causality test for the 111 examination of the relationship between nuclear energy consumption and carbon 112 emissions for 30 countries known for high consumption of the energy. The study finds 113 evidence in support of a favourable effect of nuclear energy consumption on the 114 environment as a negative relationship exists between the variables. Examining five 115 countries belonging to the Association of Southeast Asian Nations (ASEAN), Chandran 116 and Tang (2013) discover a bidirectional relationship between energy consumption of 117 the transportation sector and carbon emissions in Malaysia and Thailand. Using a 118 different methodology-simultaneous equation model, a unidirectional causal effect 119 running from energy consumption to carbon emissions is confirmed for 14 Middle East 120 and North Africa (MENA) countries by Omri (2013).

121 The recent study of Zoundi (2017) considers the renewable energy consumption-carbon 122 emissions nexus for 25 African countries and establishes an expected decreasing impact 123 in the release of carbon emissions in the region. The study further shows that renewable 
124 energy can act as substitute for fossil fuels which have been the major sources of 125 production inputs and domestic use for a long time. Dong et al. (2017a) supports these 126 findings by revealing that the consumption of both renewable and natural gas mitigates 127 carbon emissions in BRICS countries. For different countries, other studies that confirm 128 the significant effect of energy consumption on carbon emissions, either positively or 129 otherwise include Dong et al. (2018a), Dong et al. (2017b), Kasman and Duman (2015), 130 etc.

131 The most recent line of studies on the energy consumption-environmental degradation 132 involves using ecological footprint instead of carbon emissions. In their attempt to the 133 main drivers of environmental degradation in sub-Saharan African countries, Wang 134 and Dong (2019) reveal that both non-renewable and renewable energy consumption 135 are among the determinants. In particular, non-renewable energy consumption exerts 136 positive influence on ecological footprint, while the impact is negative for renewable 137 energy consumption. Similarly, Destek et al. (2018) and Dogan et al. (2019) find that 138 environmental degradation worsens with rising energy consumption in both EU and 139 MINT countries respectively. Meanwhile, a few studies favour country-specific 140 analysis. For instance, Imamoglu (2018) confirms energy consumption as one of the 141 driving factors of ecological footprint in Turkey. The findings of Khan et al. (2020) 142 appear similar to that of Imamoglu (2018), although it additionally puts asymmetries 143 into consideration. Their nonlinear Autoregressive Distributed Lag (NARDL) model 144 suggests asymmetric relationship between energy consumption and ecological footprint 
145 in Pakistan in the long-run. However, Ozcan et al. (2019) reveal contrary evidence with 146 respect to non-renewable consumption. Their findings show that the patterns of energy 147 consumption enhance the environmental performance of the OECD countries, 148 indicating that the environmental policies of the countries are beginning to be aligned 149 with through their efficient energy consumption patterns.

150 Thus, it remains true based on the above reviews that there is scarcity of empirical 151 information on the impact of energy consumption on the ecological footprint in the 152 OPEC countries. As noted earlier, these countries play significant role in the production 153 (and consequently the consumption due to their energy-dependent status) of crude oil 154 which doubles as the most consumed commodity globally and the highest component 155 of the non-renewable energy group. We fill this gap in this study.

\section{3. Data metrics and methodology}

\section{3.1 Data and preliminary analysis}

158 Out of the 13 member countries of the Organization of Petroleum Exporting Countries 159 (OPEC), our panel study includes 10 countries for which data are taken over the period 160 of 1990 to 2014. As much as we are willing to consider all the OPEC member countries 161 and obtain data for a larger scope, we are limited by data availability. The full sample is 162 further divided into the Middle-East and non-Middle-East countries comprising of 4 163 (Iran, Iraq, Saudi Arabia and United Arab Emirates) and 6 (Algeria, Angola, Democratic 
164 Republic of Congo, Gabon, Nigeria and Venezuela) cross-sections respectively. ${ }^{1}$ Thus, 165 we analyze the effect of energy consumption on ecological footprint for the full sample 166 and the two sub-samples. The main data are per capita ecological footprint (global 167 hectares), per capita energy consumption ( $\mathrm{kg}$ of oil equivalent), while the control 168 variables against omission bias in the estimates are per capita GDP and urban 169 population.

170 Our choice of ecological footprint as a more robust measure of environmental 171 sustainability in empirical analysis than carbon-emissions follow recent and prominent 172 studies like Ulucak and Apergis (2018), Kassouri and Altintas (2020), Wang and Dong 173 (2019), etc. Its preference over the commonly used carbon emissions as a measure of 174 environmental quality is because it encompasses more components including carbon 175 footprint, forest footprint, grazing land footprint, water footprint, cropland footprint 176 and Built-up land footprint in assessment of human impacts on nature. Additionally, it 177 helps to reveal the exact budget -biocapacity of the ecosystem, and the degree of human 178 influence on the regenerative strength of the environment (see Galli et al., 2020). Next is 179 energy consumption which is measured as the aggregate non-renewable energy 180 demand (particularly fossil fuels, including oil, coal and natural gas). Expectedly, 181 higher energy consumption should impair on environmental quality due to the

\footnotetext{
${ }^{1}$ Our consideration for the division of the OPEC countries into Middle-East and non-Middle-East is motivated by the fact that nearly one-third of the total world oil exports is accounted for by the Middle-East-based OPEC countries (see Table 1). In addition, we foreshadow our descriptive statistics and find that despite being smaller in number than the non-Middle-East countries, the Middle-East countries have higher average per capita ecological footprint and per capita energy consumption. So, we intend to discover whether the energy consumption of the region with the highest crude oil exports contribute more or less to environmental degradation, compared to their oil exporting counterparts.
} 
182

183

184

185

186

187

188

189

190

191

192

193

194

195

196

197 198 Network $^{3}$.

199

200

201

associated emission rate. Hence, a positive relationship is hypothesized between energy consumption and ecological footprint. Apart from the energy consumption, we consider other two macroeconomic indicators as potential regressors that have been adjudged to have significant influence on environmental quality. They are economic growth and degree of urbanization (see Kassouri and Altintas, 2020; Ozcan et al., 2019, Wang and Dong, 2019). We are limited to these two due to insufficient data for other series empirically identified to impact on ecological footprint. The value of Gross domestic products (GDP) is conventionally used to measure the level of economic growth of a country, while urban population is the most suitable for the degree of urbanization. Expectedly, these they should also have positive effect on ecological footprint because as an economy grows and its urban population rises, there seems to be more pressure on environmental resources that eventually causes environmental degradation. The exemption to this assertion is if the resources are efficiently utilized, and urbanization plan ensures easy access to efficient and cleaner technology.

The data for all the regressors are sourced from the World Development Indicators $(\mathrm{WDI})^{2}$, while per capita ecological footprint is obtained from Global Footprint

The preliminary analyses of the data are provided in Tables 2-3, and Figures 1-2 for the full sample and the sub-samples (which are the Middle-Eastern and non-MiddleEastern countries). Interestingly, the Middle-Eastern countries report higher average

\footnotetext{
${ }^{2}$ See https://www.datacatalog.worldbank.org/

${ }^{3}$ See https://www.footprintnetwork.org/\#/
} 
202 values for all the variables than their non-Middle-Eastern countries counterparts (see 203 Table 2). In other words, they seem to cause higher environmental degradation, 204 consume more non-renewable energy and have higher economic growth on average, 205 and higher degree of urbanization. For the correlation analysis reported in Table 3, the 206 coefficients are significant in all cases, except for ecological footprint and urbanization 207 under the non-Middle-Eastern group. While the correlation is positive for ecological 208 footprint and GDP in all cases, negative results are obtained for the correlation between 209 ecological footprint and urbanization. For most of the countries, the graphical 210 illustration shows an upward co-movement between ecological footprint and energy 211 consumption (see Figures 1 and 2).

Table 2: Descriptive statistics

\begin{tabular}{|l|l|l|l|l|l|l|}
\hline & Mean & Maximum & Minimum & Std. Dev. & Jarque- & Observation \\
& & & & Bera & \\
\hline EF & 2.9122 & 13.8500 & 0.0126 & 3.3415 & 342.7760 & 250 \\
\hline ENG & 2509.1328 & 12172.4 & 295.2240 & 2888.5829 & 235.7397 & 250 \\
\hline GDP & 11422.8816 & 68780.6 & 276.0560 & 15740.5459 & 450.7591 & 250 \\
\hline URB & 20526932 & 83000000 & 656504 & 16343684 & 97.8211 & 250 \\
\hline & & & Mull sample & \\
\hline EF & 5.0931 & 13.8500 & 1.0700 & 4.3086 & 19.0610 & 100 \\
\hline
\end{tabular}




\begin{tabular}{|l|l|l|l|l|l|l|l|}
\hline ENG & 4629.5459 & 12172.4 & 891.9120 & 3541.4404 & 11.9472 & 100 \\
\hline GDP & 20587.2494 & 68780.6 & 1432.17 & 21185.1429 & 20.6902 & 100 \\
\hline URB & 20829000 & 56000000 & 1400000 & 15317642 & 10.1766 & 100 \\
\hline EF & 1.4582 & 3.8500 & 0.0126 & 1.0023 & 5.7494 & 150 \\
\hline ENG & 1095.5242 & 3129.0800 & 295.2240 & 762.5331 & 21.2688 & 150 \\
\hline GDP & 5313.3031 & 14920.4 & 276.0560 & 4680.1077 & 18.9760 & 150 \\
\hline URB & 20325554 & 83000000 & 656504 & 17040969 & 100.7204 & 150 \\
\hline
\end{tabular}

\section{Table 3: Correlation results}

\begin{tabular}{|c|c|c|c|c|}
\hline & $\mathrm{EF}$ & ENG & GDP & URB \\
\hline \multicolumn{5}{|c|}{ Full sample } \\
\hline EF & 1 & & & \\
\hline ENG & $\begin{array}{l}0.8282^{* * *} \\
(0.0000)\end{array}$ & 1 & & \\
\hline GDP & $\begin{array}{l}0.8972^{\star * *} \\
(0.0000)\end{array}$ & $\begin{array}{l}0.9252^{* * *} \\
(0.0000)\end{array}$ & 1 & \\
\hline URB & $\begin{array}{l}-0.1806^{* * *} \\
(0.0042)\end{array}$ & $\begin{array}{l}-0.2694^{* * *} \\
(0.0000)\end{array}$ & $\begin{array}{l}-0.4077^{* * *} \\
(0.0000)\end{array}$ & 1 \\
\hline \multicolumn{5}{|c|}{ Middle-East } \\
\hline $\mathrm{EF}$ & 1 & & & \\
\hline
\end{tabular}




\begin{tabular}{|c|c|c|c|c|}
\hline ENG & $\begin{array}{l}0.9521^{\star * *} \\
(0.0000)\end{array}$ & 1 & & \\
\hline GDP & $\begin{array}{l}0.9208^{* * *} \\
(0.0000)\end{array}$ & $\begin{array}{l}0.9585^{* * *} \\
(0.0000)\end{array}$ & 1 & \\
\hline URB & $\begin{array}{l}-0.7091^{* * *} \\
(0.0000)\end{array}$ & $\begin{array}{l}-0.6702^{* * *} \\
(0.0000)\end{array}$ & $\begin{array}{l}-0.7479^{* * *} \\
(0.0000)\end{array}$ & 1 \\
\hline \multicolumn{5}{|c|}{ Non-Middle-East } \\
\hline EF & 1 & & & \\
\hline ENG & $\begin{array}{l}0.7984^{\star \star *} \\
(0.0000)\end{array}$ & 1 & & \\
\hline GDP & $\begin{array}{l}0.8907^{* * *} \\
(0.0000)\end{array}$ & $\begin{array}{l}0.9030^{* * *} \\
(0.0000)\end{array}$ & 1 & \\
\hline URB & $\begin{array}{l}-0.1338 \\
(0.1027)\end{array}$ & $\begin{array}{l}-0.2729^{* * *} \\
(0.0007)\end{array}$ & $\begin{array}{l}-0.3922^{* * *} \\
(0.0000)\end{array}$ & 1 \\
\hline
\end{tabular}

216 Values in parentheses are probabilities. ${ }^{* * *}$ indicates significance at $1 \%$ critical level. 

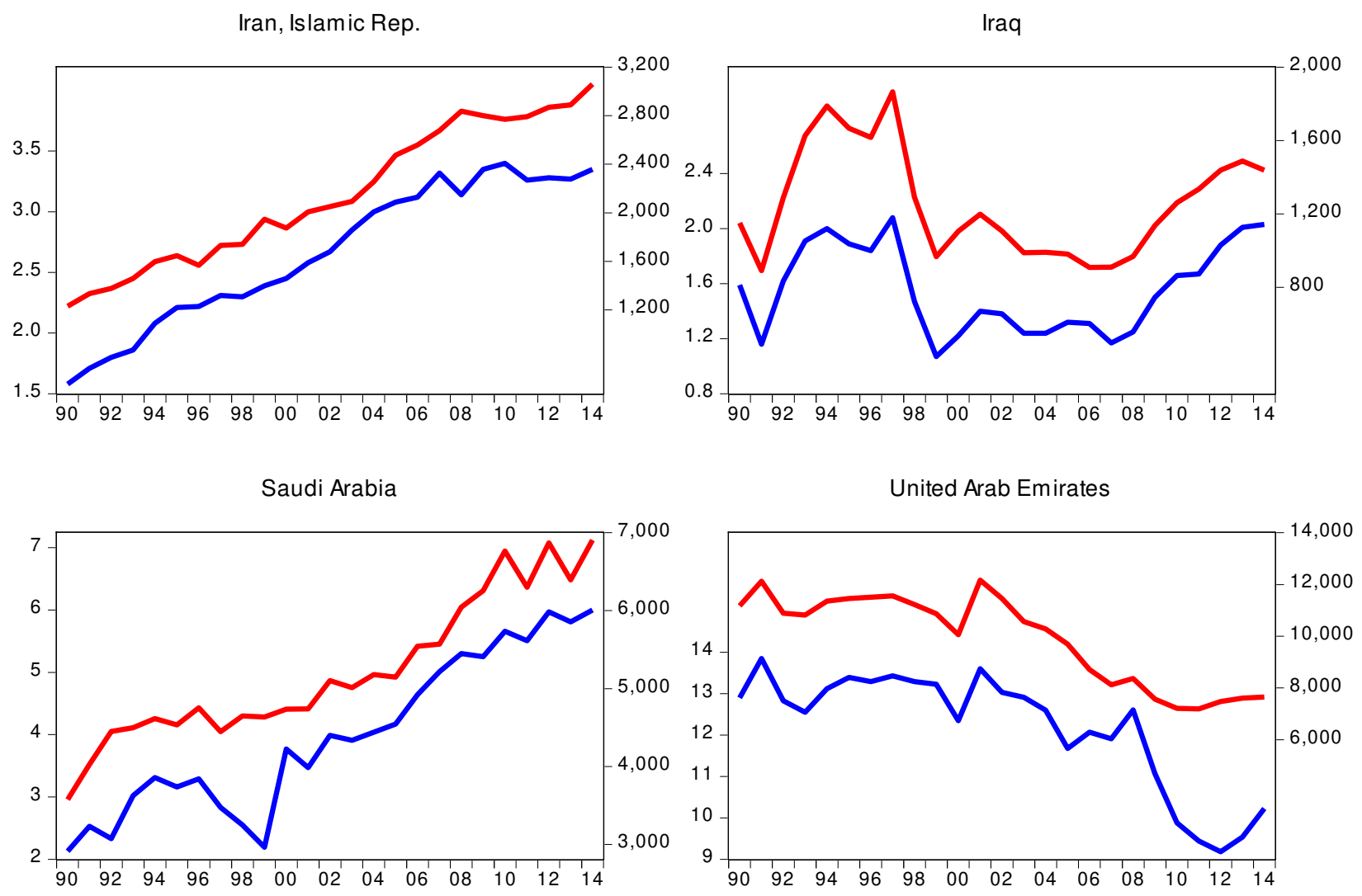

218 Figure 1: Trends in ecological footprint and energy consumption in Middle-Eastern 219 countries 


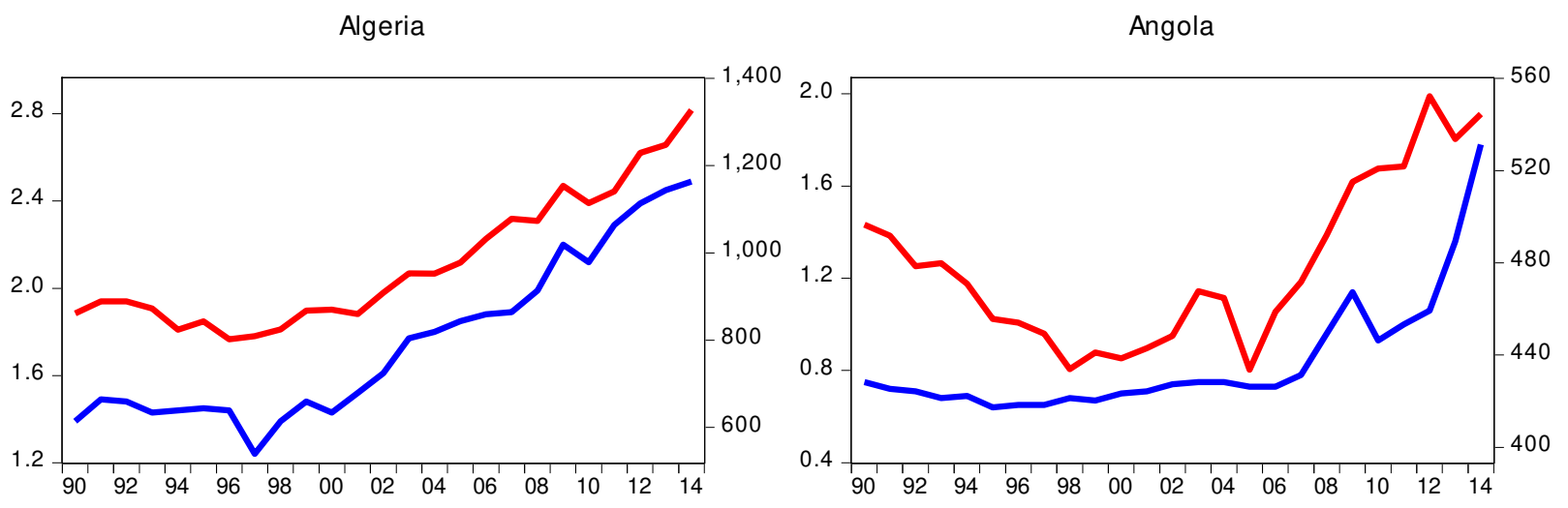

Congo, Dem. Rep.

Gabon
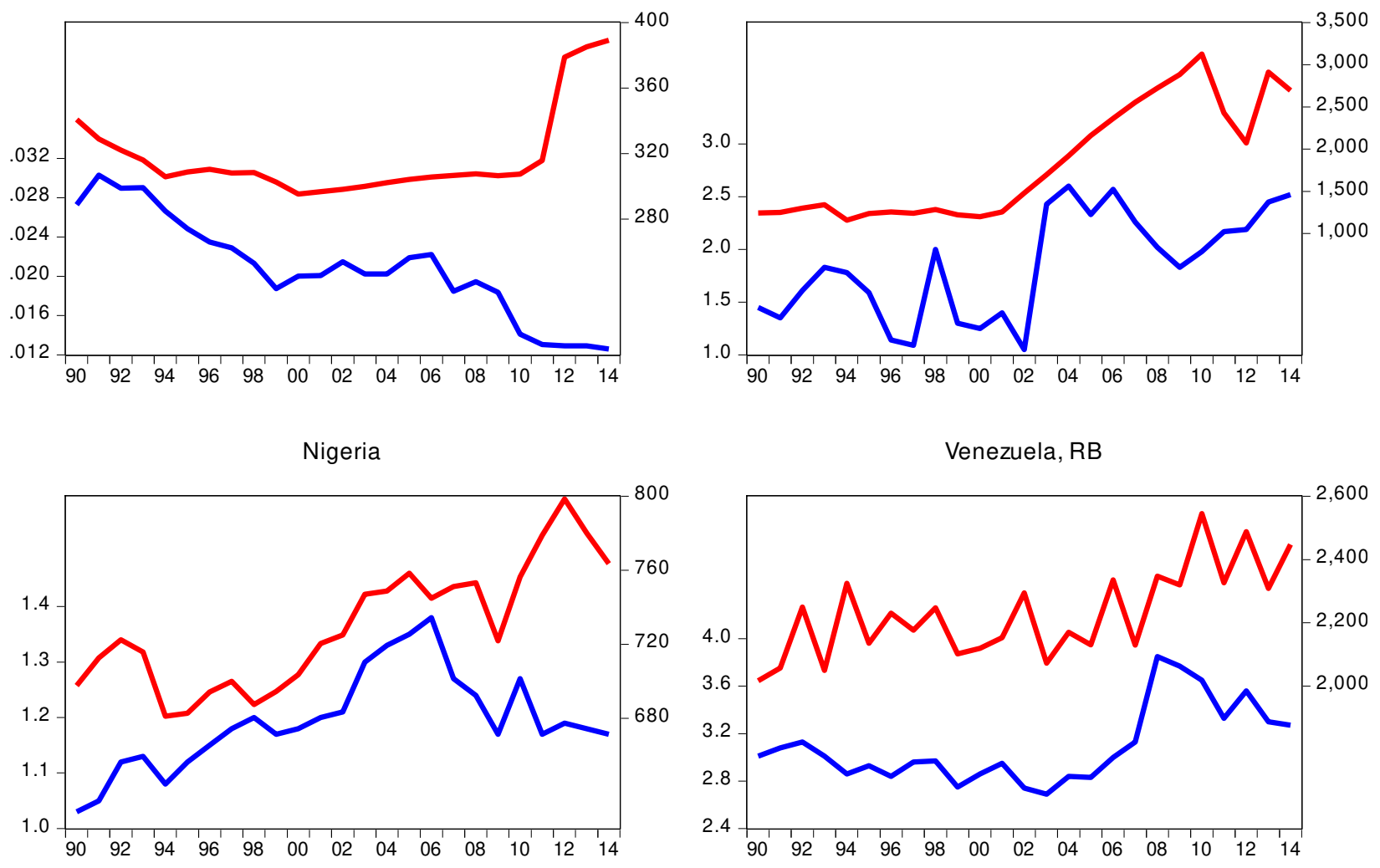

222 Figure 2: Trends in ecological footprint and energy consumption in non-Middle-

223 Eastern countries

$224 \quad 3.2$ Methodology 
225 Prior to recent times, the empirical techniques applied in panel data analysis could not 226 account for some inherent characteristics of panel series, such as cross-sectional 227 dependence and heterogeneity. In order to ensure better estimates, our analysis in this 228 study relies on the second generation estimators that are able to handle these statistical 229 features. On this note, our methodological framework begins with the specification of 230 the test for cross-sectional dependence in the panel series. If we are able to establish that 231 dependence is inherent among the cross-sections, we proceed to assessing the 232 stationarity properties of the panel series using panel unit root tests that can 233 accommodate cross-sectional dependence. From the unit root test, we will be able to 234 establish integration order of the panel series. If all the series are non-stationarity 235 results, i.e. I(1), then we check for the possibility of long-run relationship among the 236 variables using the technique of Westerlund (2007). Lastly, long-run estimation among 237 is carried out using standard econometric estimators that conveniently account for the 238 statistical and econometric issues raised above. For clarity, we employ the Common 239 Correlated Effects Mean Group (CCEMG) due to Pesaran (2006) and the Augmented 240 Mean Group (AMG) proposed by Eberhardt and Bond (2009). Although the results of 241 both estimators are presented for estimation, we rely essentially on the latter for 242 discussion because of its superiority over the former.

243 Therefore, for our empirical analysis, the econometric relationship between ecological 244 footprint and the regressors is specified thus:

$$
E F_{i t}=\omega_{0}+\omega_{1} E N G_{i t}+\omega_{2} G D P_{i t}+\omega_{3} U R B_{i t}+\varepsilon_{i t} ; \quad i=1,2, \ldots, N ; t=1,2, \ldots T
$$


246 where $E F, E N G, G D P$ and $U R B$ represent ecological footprint per capita, non-renewable 247 energy consumption per capita, gross domestic products per capita and urban 248 population respectively. $\varepsilon$ is the error term. All the variables are logarithmically 249 transformed.

\subsubsection{Cross-sectional dependence tests}

251 Cross-sections among panel members can be caused by a host of factors including 252 spatial effects and socioeconomic interactions, policy interplay. Not accounting for them 253 could cause estimation bias (see Dong et al. 2018d). In light of this, we test for cross254 sectional dependence using approaches of Breush and Pagan (1980) and Pesaran (2004).

255 We start with the specification of the Langrange Multiplier (LM) statistic put forward 256 by Breush and Pagan (1980) thus:

$$
L M_{B P}=\sum_{k=1}^{N-1} \sum_{l=k+1}^{N} \hat{\beta}_{i l}^{2}
$$

258 where $\hat{\beta}_{i l}^{2}$ denotes the estimated sample of the coefficient of the pair-wise correlation 259 of the residuals obtained from the Ordinary Least Squares (OLS) estimations. $L M_{B P}$ is 260 assumed to be asymptotically distributed with the chi-square degrees of freedom of $261 \frac{1}{2}\left(N^{2}-N\right)$. Meanwhile, the validity of the LM test for the null hypothesis of absence of 262 cross-sectional dependence relates to panel series in which $T \rightarrow \infty$ and $\mathrm{N}$ is fixed. If on 263 the other hand $N \rightarrow \infty$ and T is fixed, the rescaled version of the $L M_{B P}$ test is developed 264 by Pesaran (2004) thus: 


$$
L M_{P S}=\sum_{k=1}^{N-1} \sum_{l=k+1}^{N}\left(\hat{\beta}_{i l}^{2}-1\right) \sim N(0,1)
$$

266 It is further noted for large $\mathrm{N}$ and small $\mathrm{T}$ panel series that the $L M_{P S}$ test in equation (3) 267 can show significant size distortions. This eventually results in the development of an 268 improved test that is capable of handing large $\mathrm{T}$ and large $\mathrm{N}$ (i.e. $N \rightarrow \infty$ and $T \rightarrow \infty$ ) by 269 Pesaran (2004):

270

$$
C D_{P E S}=\sqrt{\left(\frac{2 T}{N^{2}-N}\right)}\left(\sum_{k=1}^{N-1} \sum_{l=k+1}^{N} \hat{\beta}_{i l}^{2}\right) \sim N(0,1)
$$

271 The last cross-sectional dependence test is the bias-adjusted LM statistic developed by

272 Pesaran et al. (2008). According to Pesaran (2004), the $C D_{P E S}$ test in equation (4) is

273 consistent for heterogeneous dynamic panel models that include structural breaks in the

274 error variances and/or slope coefficients. However, when the average cross-section of 275 the factor loading tends to zero, the $C D_{P E S}$ test becomes inconsistent. Therefore, the bias276 adjusted kind of the LM tests which considers the variance and the exact mean of the 277 LM statistic was proposed by Pesaran et al (2008). This is given as:

278

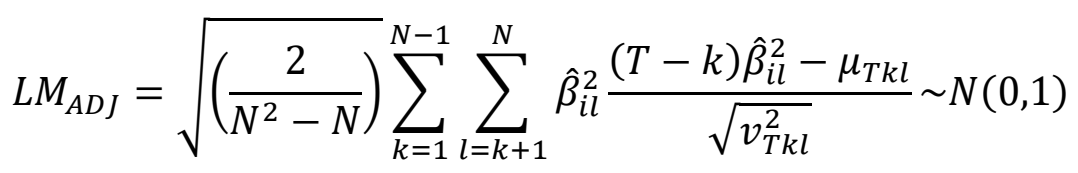

279 where the number of explanatory variables is denoted by $k$, while the exact mean and 280 variance of $(T-k) \hat{\hat{\beta}}_{i l}^{2}$ are respectively $\mu_{T k l}$ and $v_{T k l}^{2}$.

\subsubsection{Panel unit root tests}


282 Our next focus is the examination of the stationarity properties of the panel series. We 283 engage the Cross-sectionally Augmented Dickey-Fuller (CADF) and Cross-sectionally 284 Augmented Im, Pesaran and Shin (CIPS) panel unit root tests developed by Pesaran $285 \quad(2007)$

$$
\Delta y_{i t}=\alpha_{0}+\alpha_{1} y_{i, t-1}+\alpha_{2} \bar{y}_{t-1}+\sum_{k=1}^{p} \beta_{1 i k} \Delta \bar{y}_{i, t-k}+\sum_{l=0}^{q} \beta_{2 i k} \Delta y_{t-k}+\varepsilon_{i t}
$$

287 where $\bar{y}_{t-k}$ and $\Delta \bar{y}_{t-k}$ denote the averages of the cross-sections in their lagged levels 288 and first differences. Following this, the CIPS panel unit root is now given thus:

$$
C I P S=N^{-1} \sum_{i=1}^{N} C A D F_{i}
$$

290 The critical values of the CIPS panel unit root test are computed in Pesaran (2007).

291 Another notable advantage of the CIPS test is that it can account for autocorrelation (see

292 Kassouri and Altintas, 2020).

\subsubsection{Westerlund (2007) panel cointegration test}

294 Conventional panel cointegration tests, such as the Pedroni cointegration test, break 295 down if the panel members show evidence of cross-sectional dependence. Accordingly, 296 we employ an advanced cointegration test due to Westerlund (2007) that is able to 297 handle this issue. It is specified thus:

298

$$
\Delta y_{i t}=\gamma_{i}^{\prime} d_{t}+\vartheta_{i} y_{i, t-1}+\iota_{i}^{\prime} x_{i, t-1}+\sum_{j=1}^{p_{i}} \vartheta_{1 i j} \Delta y_{i, t-j}+\sum_{j=-k_{i}}^{q_{i}} \vartheta_{2 i j} \Delta x_{i, t-j}+\varepsilon_{i t}
$$


299 where $d_{t}$ denotes the deterministic component, which can be of three forms. The first 300 case is when $d_{t}=0$, implying equation (8) has no deterministic terms. In the second 301 scenario, $d_{t}=1$, implying that $\Delta y_{i t}$ is generated with an intercept. The last case scenario 302 is when $\Delta y_{i t}$ is generated with both intercept and trend, such that $d_{t}=(1, t)^{\prime} . \vartheta_{i}$ is the 303 parameter that determines the speed of adjustment to long-run equilibrium. If $\vartheta_{i}<0$, 304 error correction exists, indicating that $y_{i t}$ and $x_{i t}$ have long-run relationship. On the 305 other hand, if $\vartheta_{i}=0$, error correction does not hold, hence there is no cointegration. The 306 overall null hypothesis of no cointegration is thus given as $H_{0}: \vartheta_{i}=0$ for all $i$. In 307 addition, Westerlund (2007) developed two pairs of statistics in relation to the 308 cointegration test. The first pair is for the group mean which does not require the 309 equality of the $\vartheta_{i} \mathrm{~s}$. This further indicates that the testing of $H_{0}$ against the alternative 310 $H_{1}^{g}: \vartheta_{i}<0$ is only for at least one $i$. The second pair, called the panel tests, is for the case

311 of $\vartheta_{i}$ being equal for all $i$. Hence, $H_{0}$ is tested against the alternative $H_{1}^{p}: \vartheta_{i}=\vartheta<0$ for 312 all $i$.

\subsubsection{Panel long-run estimators}

314 In order to obtain estimates that are free of potential bias due to the aforementioned 315 properties of panel series, the long-run estimators favoured in this study are the 316 CCEMG and AMG. They both observe two-stage estimation procedure. Starting with 317 the CCEMG estimator, it augments the baseline regression model with cross-section 318 means of the dependent variable and the observed regressors, so that they are made as 319 proxies for the unobserved common factors. It is specified thus: 
322 where $y_{i t}$ is the dependent variable, which in this case is ecological footprint, and the 323 regressors are contained in $x_{i t} . \widehat{\emptyset}_{C C E M G}$ is the estimated coefficient of the CCEMG 324 estimator. As rightly noted by Seven et al. (2018), the CCEMG estimator provides 325 consistent estimates even when there is correlation between the observed regressors 326 and the common factors. In addition, it is robust to heterogeneity of slope parameters, 327 endogeneity, cross-sectional dependence, non-stationarity and structural breaks.

328 On its own, the AMG estimator differentiates the impact of the observed and 329 unobserved common factors in the panel group. To consider cross-sectional dependence 330 of the panel members, Eberhardt and Bond (2009) introduced a common dynamic effect 331 which is in form of year dummy coefficients in order to indicate how the unobserved 332 common factors of the cross-sections evolve in their levels-equivalent form. The two333 stage specification is given thus:

$$
\text { Stage 2: } \quad \widehat{\emptyset}_{A M G}=N^{-1} \sum_{i=1}^{N} \widehat{\emptyset}_{i}
$$

336 where country-specific parameters are indicated by $\emptyset_{i}$, the unobserved common factor 337 with heterogenous feature is denoted by $f_{t}$, and the time dummy parameters of $D_{t}$ 338 which are also called the common dynamic process is represented by $\rho_{i}$. $\widehat{\emptyset}_{A M G}$ 339 represents the augmented mean group estimator. A major advantage of the AMG 
340 estimator over the CCEMG estimator, however, is that the former gives economic

341 meaning to the unobserved factors treated as nuisance parameters in the latter.

\section{4. Empirical findings and discussion}

343 For the sake of brevity, the results are presented and discussed under relevant 344 headings. We begin with the discussion of the relevant characteristics of panel data that 345 inform our choice of estimator.

\section{$346 \quad 4.1$ Cross-sectional dependence tests results}

347 It is important to check for interdependence of the cross-sections, which in this case are 348 the countries under consideration, as not accounting for this feature can induce 349 significant bias to the estimates. For robustness, we employ four notable tests to check 350 for this tendency, and the results are presented in Table 4 for the full and sub-samples.

351 Evidently, the null hypothesis of no cross-sectional dependence is resoundingly rejected 352 in all cases. This suggests that, irrespective of the sub-sample, cross-sectional 353 dependence is found for all the panel members, and so, second generation unit root and 354 cointegration tests that are consistent with this issue are employed. The results are 355 discussed in the next sub-section.

\section{$356 \quad 4.2$ Unit root tests results}

357 Having discovered the presence of cross-sectional dependence in our panel members, 358 we employ two standard unit root tests which have been adjudged to produce unbiased 359 results to determine the stationarity levels of the panel series. Presented in Table 5, both 
360 Pesaran CADF and Pesaran CIPS tests show that the unit root null hypothesis cannot be

361 rejected for all the series across all the sub-samples, except urban population. This

362 further implies that, except urban population that observes level-stationary (i.e. I(0)),

363 they are non-stationary (i.e. I(1)). Usually, non-stationary series can either be

364 cointegrated or produce spurious results. Hence, we apply the cointegration test in the 365 next section to determine if the series have long-run relationship.

\section{$366 \quad 4.3$ Cointegration test results}

367 Subsequent on the evidence of mixed intrgration order of series, with most indicating 368 non-stationarity, we utilize the cointegration test due to Westerlund (2007) in order to

369 trace out any possible long-run relationship among the panel series. The choice of this

370 test, as against the commonly utilized ones in former panel studies, is due to the initial

371 evidence of cross-sectional dependence of our panel members. While the test has the

372 null hypothesis of no cointegration, the alternative hypothesis is dependent on the

373 specific test. The alternative hypothesis of at least one cointegrated unit is examined by

374 the group-mean tests (symbolized by $G_{t}$ and $G_{a}$ ), while the alternative hypothesis of 375 panel cointegration as a whole is examined by the panel tests (symbolized by $\mathrm{P}_{\mathrm{t}}$ and $\mathrm{P}_{\mathrm{a}}$ ) 376 (see Burret et al., 2014). Meanwhile, owing to the fact that the results may be sensitive to 377 lags, leads and kernel width choices due to the limited number of cross-sections, 378 especially for the sub-samples, different specifications (unrestricted and restricted cases) 379 of each cointegration test are estimated. In addition, we first conduct the test following 380 the original consideration of Westerlund (2007) which considers only one regressor 
381 (which in this case is the energy consumption), and then extend it to include other 382 regressors (which are gross domestic products and urban population). The results are 383 provided in Table 6. In the upper panel of Table 6, the results for the approach of 384 Westerlund (2007) approach suggests for both the unrestricted and restricted cases that 385 the null hypothesis of no cointegration is rejected in virtually all cases. In the lower 386 panel which reports for the multiple regressors, there is evidence of cointegration 387 among the variables for only the group mean under the unrestricted case. Undoubtedly, 388 the reason for the insignificance of the panel tests is because of the sensitivity of the 389 tests to number of lags and leads. When this is put into consideration in the restricted 390 case, a better cointegration performance is obtained for the panel tests.

391 In essence, it is worth concluding that there is significant evidence of long-run 392 relationship among our panel series. Based on this evidence, it is appropriate to proceed 393 to the regression analysis where the impact of energy consumption (and other 394 regressors, namely gross domestic products and urban population) on ecological 395 footprint is examined.

396 Table 4: Results of cross-sectional dependence tests

\begin{tabular}{|l|l|l|l|l|l|}
\hline & EF & ENG & GDP & URB & OIL \\
\hline \multicolumn{5}{|c|}{ Full sample } \\
\hline LM $_{\text {BP }}$ & $396.0990^{* * *}$ & $475.2956^{* * *}$ & $493.9363^{* * *}$ & $1100.5635^{* * *}$ & $1125.0000^{* * *}$ \\
\hline LMPS & $35.9550^{* * *}$ & $44.3031^{* * *}$ & $46.2680^{* * *}$ & $110.2121^{* * *}$ & $112.7879^{* * *}$ \\
\hline LM $_{\text {ADJ }}$ & $35.7467^{* * *}$ & $44.0947^{* * *}$ & $46.0596^{* * *}$ & $110.0037^{* * *}$ & $112.5796^{* * *}$ \\
\hline
\end{tabular}




\begin{tabular}{|c|c|c|c|c|c|}
\hline$C_{\text {PES }}$ & $2.7477^{* * *}$ & $9.2178^{* * *}$ & $2.8564^{\star \star \star}$ & $33.1737^{* * *}$ & $33.5410^{* * *}$ \\
\hline \multicolumn{6}{|c|}{ Middle-East } \\
\hline $\mathbf{L} \mathbf{M}_{\mathrm{BP}}$ & $51.0228^{\star * *}$ & $62.4193^{* * *}$ & $53.3079^{* * *}$ & $145.1818^{\star * *}$ & $150.0000^{* * *}$ \\
\hline LMPS & $11.8423^{* * *}$ & $15.1321^{* * *}$ & $12.5019 * * *$ & $39.0236^{* * *}$ & $40.4145^{\star \star *}$ \\
\hline $\mathbf{L M}_{\mathrm{ADJ}}$ & $11.7589^{* * *}$ & $15.0488^{* * *}$ & $12.4186^{* * *}$ & $38.9402^{* * *}$ & $40.3312^{* * *}$ \\
\hline CDPES & $-1.7430^{*}$ & $-1.9685^{\star *}$ & $-1.9363^{*}$ & $12.0486^{* * *}$ & $12.2475^{* * *}$ \\
\hline \multicolumn{6}{|c|}{ Non-Middle-East } \\
\hline $\mathbf{L M}_{\mathrm{BP}}$ & $120.6069^{* * *}$ & $160.3966^{* * *}$ & $162.0705^{\star * *}$ & $368.3891^{* * *}$ & $375.0000^{* * *}$ \\
\hline LMPS & $18.1856^{* * *}$ & $25.4502^{* * *}$ & $25.7558^{* * *}$ & $63.4243^{* * *}$ & $64.6313^{* * *}$ \\
\hline $\mathbf{L M}_{\mathrm{ADI}}$ & $18.0606^{* * *}$ & $25.3252^{* * *}$ & $25.6308^{* * *}$ & $63.2993^{* * *}$ & $64.5063^{* * *}$ \\
\hline $\mathrm{CD}_{\mathrm{PES}}$ & $2.2815^{* *}$ & $12.2336^{* * *}$ & $2.0454^{* *}$ & $19.1931^{* * *}$ & $19.3649^{* * *}$ \\
\hline
\end{tabular}

*** and ${ }^{* *}$ indicate significance at $1 \%$ and $5 \%$ critical levels respectively.

Table 5: Results of Panel unit root tests

\begin{tabular}{|l|l|l|l|l|l|l|}
\hline & & CADF & & & CIPS & \\
\cline { 2 - 7 } & Level & Ist Diff. & I(d) & Level & Ist Diff. & I(d) \\
\hline EF & -1.904 & $-3.453^{* * *}$ & $\mathrm{I}(1)$ & -1.984 & $-4.900^{* * *}$ & $\mathrm{I}(1)$ \\
\hline ENG & -2.004 & $-3.528^{* * *}$ & $\mathrm{I}(1)$ & -2.556 & $-5.397^{* * *}$ & $\mathrm{I}(1)$ \\
\hline GDP & -1.845 & $-3.120^{* * *}$ & $\mathrm{I}(1)$ & -2.219 & $-3.879^{* * *}$ & $\mathrm{I}(1)$ \\
\hline URB & $-2.863^{* *}$ & $-2.730^{* * *}$ & $\mathrm{I}(0)$ & $-3.993^{* * *}$ & $-5.898^{* * *}$ & $\mathrm{I}(0)$ \\
\hline
\end{tabular}




\begin{tabular}{|c|c|c|c|c|c|c|}
\hline \multicolumn{7}{|c|}{ Middle-East } \\
\hline EF & -1.226 & $-3.428 * * *$ & $\mathrm{I}(1)$ & -2.352 & $-5.960^{\star * *}$ & $\mathrm{I}(1)$ \\
\hline ENG & -0.603 & $-3.260^{* *}$ & $\mathrm{I}(1)$ & -2.703 & $-5.889^{* * *}$ & $\mathrm{I}(1)$ \\
\hline GDP & -2.116 & $-3.184^{* *}$ & $\mathrm{I}(1)$ & -1.652 & $-4.158^{* * *}$ & $\mathrm{I}(1)$ \\
\hline URB & $-4.225^{* * *}$ & $-3.724^{\star * *}$ & $\mathrm{I}(0)$ & -5.928 & $-5.561^{* * *}$ & $\mathrm{I}(0)$ \\
\hline \multicolumn{7}{|c|}{ Non-Middle-East } \\
\hline EF & -1.888 & $-3.599 * * *$ & $\mathrm{I}(1)$ & -1.861 & $-4.765^{* * *}$ & $\mathrm{I}(1)$ \\
\hline ENG & -2.042 & $-3.881^{* * *}$ & $\mathrm{I}(1)$ & -2.496 & $-5.689^{* * *}$ & $\mathrm{I}(1)$ \\
\hline GDP & -1.548 & $-0929^{*}$ & $\mathrm{I}(1)$ & -1.280 & $-3.621^{* * *}$ & $\mathrm{I}(1)$ \\
\hline URB & $-2.872^{*}$ & $-5.633^{* * *}$ & $\mathrm{I}(0)$ & $-3.871^{* * *}$ & $-6.420^{* * *}$ & $\mathrm{I}(0)$ \\
\hline
\end{tabular}

400 For the CIPS unit root test, the critical values are computed by Pesaran (2007) as -3.1, -

4012.86 and -2.73 for $1 \%, 5 \%$ and $10 \%$ significance levels respectively. Also, ***, ** and * 402 indicate significance at $1 \%, 5 \%$ and $10 \%$ critical levels respectively.

404 Table 6: Results of Westerlund (2007) panel cointegration test

\begin{tabular}{|l|l|l|l|l|l|l|}
\hline Statistics & \multicolumn{2}{l}{$\begin{array}{l}\text { Unrestricted case } \\
\text { selection) }\end{array}$} \\
\hline \multirow{8}{*}{ Full } & Middle- & Non- & Full & Middle- & Non- \\
& sample & East & Middle- & sample & East & Middle- \\
& countries & East & & countries & East \\
\hline \multicolumn{7}{|c|}{ Replication of Westerlund (2007) } \\
\hline
\end{tabular}




\begin{tabular}{|l|l|l|l|l|l|l|}
\hline $\mathbf{G}_{\mathbf{t}}$ & $-3.307^{* * *}$ & $-3.232^{* * *}$ & $-3.358^{* * *}$ & $-2.971^{* * *}$ & $-2.944^{*}$ & $-2.989^{* *}$ \\
\hline $\mathbf{G}_{\mathbf{a}}$ & $-22.889^{* * *}$ & -15.650 & $-27.715^{* * *}$ & $-21.718^{* * *}$ & -13.825 & $-26.979^{* * *}$ \\
\hline $\mathbf{P}_{\mathbf{t}}$ & $-9.128^{* * *}$ & $-6.122^{* *}$ & $-6.961^{* *}$ & $-9.205^{* * *}$ & $-7.027^{* * *}$ & $-6.773^{* *}$ \\
\hline $\mathbf{P}_{\mathbf{a}}$ & $-18.085^{\star * *}$ & $-17.051^{* * *}$ & $-18.451^{* * *}$ & $-18.880^{\star * *}$ & $-16.987^{* * *}$ & $-19.459^{* * *}$ \\
\hline \multicolumn{7}{|c|}{ Multiple regressors } \\
\hline $\mathbf{G}_{\mathbf{t}}$ & $-13.291^{* * *}$ & $-23.579^{* * *}$ & $-6.433^{* * *}$ & $-12.991^{* * *}$ & $-23.294^{* * *}$ & $-6.123^{* * *}$ \\
\hline $\mathbf{G}_{\mathbf{a}}$ & -0.564 & -0.289 & -0.748 & -0.296 & -0.252 & -0.326 \\
\hline $\mathbf{P}_{\mathbf{t}}$ & -4.456 & -2.166 & -4.350 & $-10.014^{* * *}$ & -4.331 & $-9.360^{\star * *}$ \\
\hline $\mathbf{P}_{\mathbf{a}}$ & -3.218 & -5.129 & -2.944 & -0.298 & 3.100 & -0.287 \\
\hline
\end{tabular}

$\mathrm{G}_{\mathrm{t}}$ and $\mathrm{G}_{\mathrm{a}}$ denote group mean tests, while $\mathrm{P}_{\mathrm{t}}$ and $\mathrm{P}_{\mathrm{a}}$ denote panel mean tests. ***, ** and * indicate significance at $1 \%, 5 \%$ and $10 \%$ critical levels respectively.

\subsection{Estimated results}

We report the results of both CCEMG and AMG estimators for the full sample as well as the sub-samples, i.e. MENA and non-MENA countries. With respect to the impact of

411 energy consumption on ecological footprint, the results of both models are really

412 similar, particularly in terms of significance (see Table 7). However, a few differences

413 are found in the significance of GDP and urban population, as the results of the AMG

414 produce better results than those of the CCEMG. This perhaps justifies our preference 415 of the AMG estimator which has been empirical adjudged to perform better than the 
416 CCEMG estimator (see Eberhardt and Bond, 2009). We therefore base our explanation

417 on the results of the AMG estimates.

418 Starting with the full sample results, it is seen from Table 6 that ecological footprint

419 responds positively to energy consumption. This means that for the entire OPEC group,

420 the move for higher level of energy consumption has significant increasing effect on

421 environmental degradation, thereby inducing challenges for environmental balance. For

422 specificity, a unit percent increase per capita energy consumption raises per capita

423 ecological footprint by $0.7595 \%$. In the same vein, urbanization is also found to have

424 significant and increasing impact on ecological footprint, but such evidence is not

425 established for economic growth. Our findings are consistent with those of Wang and

426 Dong (2019), Solarin and Al-Mulali (2018), Wang et al. (2016), and Li and Lin (2015),

427 among others, who disclose a positive relationship between environment degradation

428 with either or both of energy consumption and urbanization.

429 Turning to the sub-samples, similar findings as the full sample are found for both cases,

430 i.e. MENA and non-MENA countries. In other words, both energy consumption and

431 urbanization are significant positive influencers of ecological footprint, while economic

432 growth seems not to matter still. However, the differences relate to the magnitude of 433 effect, which is the major reason for the partitioning. We find from Table 7 that despite 434 the MENA countries being the highest exporters of crude oil, highest per capita 435 consumers of energy (as reported in Table 2 under descriptive statistics), and highest 436 producer of per capita ecological footprint (see Table 2), the marginal contribution of 
437 their energy consumption to environmental degradation seems smaller than that of the 438 non-Middle-East countries. For instance, while a 1\% increase in energy consumption of 439 the non-Middle-East countries increases ecological footprint by $0.8081 \%$, energy 440 consumption increase of the same magnitude in the Middle-East countries only increase 441 ecological footprint by $0.7486 \%$. It could only imply therefore that, although the Middle-

442 Eastern countries are still largely energy inefficient following their high carbon release 443 (see Bayomi and Fernandez, 2019), they still seem to perform better in energy efficiency 444 than other OPEC member countries.

445 Considering the control variables, while economic growth remains insignificant still, 446 urbanization is positively significant in both cases, with greater effect going to the non447 Middle-East countries again. We can rationalize the positive impact of urbanization on 448 ecological footprint on the argument that increasing level of urban population mounts 449 pressure and consequently increases human demands on ecological resources. The 450 resultant effect is increasing degradation of the environment.

451 In order to add precision to our analysis, we further provide the long run estimates of 452 the group-specific parameters based on our AMG estimator. The essence is to discover 453 the contribution of each country in addition to the estimates of the common dynamic 454 process of the AMG estimator. The results are reported in Tables 8 and 9 for the Middle455 East and non-Middle-East countries respectively. In the Middle-East group, energy 456 consumption of Iran seems to have higher impact on ecological degradation $(0.8907 \%)$ 457 followed by Saudi Arabia (0.8796\%). UAE is seen to impact ecological footprint the 
458 lowest. However, the highest effect of urbanization seems to be in favour of Saudi 459 Arabia with a value of $1.0076 \%$ while UAE still the least contribution still $(0.1839 \%)$.

460 Across board, GDP is not found to be significant except in Iran where the impact is 461 negative.

462 For the category of the countries not belonging to the Middle-East, energy consumption 463 has the highest impact on ecological footprint in Angola (2.1841\%). In fact, the impact is 464 more than twice as Nigeria that has the second highest impact with a value of $1.0218 \%$. 465 Interestingly, Democratic Republic of Congo seems to be the only country whose 466 energy consumption does not have adverse impact on environmental quality. The 467 negative relationship between her energy consumption and ecological footprint (468 0.7388) suggests that energy consumption has reducing effect on environmental 469 degradation. Also, economic growth in Nigeria helps to mitigate environmental 470 degradation by the negative coefficient of GDP, while contrary evidence is found for

471 Venezuela. Expectedly, ecological footprint is found to respond positively to 472 urbanization in all the countries, except Democratic Republic of Congo where the 473 impact is insignificant.

474 Table 7: Panel regressions results of CCEMG and AMG

\begin{tabular}{|l|l|l|l|l|l|l|}
\hline Variable & \multicolumn{2}{|l|}{ Full sample } & \multicolumn{2}{l|}{ Middle-East countries } & \multicolumn{2}{l|}{ Non-Middle-East } \\
& \multicolumn{2}{|l|}{ countries } \\
\cline { 2 - 7 } & CCEMG & AMG & CCEMG & AMG & CCEMG & AMG \\
\hline ENG & $0.6816^{\star \star *}$ & $0.7595^{\star \star *}$ & $0.7805^{\star \star *}$ & $0.7486^{\star \star *}$ & $0.6918^{\star * *}$ & $0.8081^{* *}$ \\
\hline
\end{tabular}




\begin{tabular}{|c|c|c|c|c|c|c|}
\hline & $(0.2157)$ & $(0.2258)$ & $(0.1687)$ & $(0.0789)$ & $(0.2229)$ & $(0.3843)$ \\
\hline GDP & $\begin{array}{l}0.1806 \\
(0.1630)\end{array}$ & $\begin{array}{l}0.1412 \\
(0.1268)\end{array}$ & $\begin{array}{l}0.2517 \\
(0.1540)\end{array}$ & $\begin{array}{l}-0.0221 \\
(0.1150)\end{array}$ & $\begin{array}{l}-0.0779 \\
(0.2993)\end{array}$ & $\begin{array}{l}0.2283 \\
(0.2101)\end{array}$ \\
\hline URB & $\begin{array}{l}0.7311 \\
(0.4450)\end{array}$ & $\begin{array}{l}0.8440^{\star * *} \\
(0.1656)\end{array}$ & $\begin{array}{l}0.9329^{* *} \\
(0.4378)\end{array}$ & $\begin{array}{l}0.6552^{* * *} \\
(0.2071)\end{array}$ & $\begin{array}{l}0.2754 \\
(0.3209)\end{array}$ & $\begin{array}{l}0.9469^{* * *} \\
(0.1976)\end{array}$ \\
\hline Constant & $\begin{array}{l}-4.3757 \\
(5.2832)\end{array}$ & $\begin{array}{l}-20.4115^{\star * *} \\
(3.0919)\end{array}$ & $\begin{array}{l}-4.7292 \\
(6.6243)\end{array}$ & $\begin{array}{l}-15.6341^{* \star *} \\
(3.1505)\end{array}$ & $\begin{array}{l}-4.5884 \\
(7.5980)\end{array}$ & $\begin{array}{l}-23.1606^{\star * *} \\
(4.9370)\end{array}$ \\
\hline \multicolumn{7}{|l|}{ Diagnostics } \\
\hline $\begin{array}{l}\text { Wald chi-sq. } \\
\text { [Prob.] }\end{array}$ & $\begin{array}{l}14.05^{* * *} \\
{[0.0028]}\end{array}$ & $\begin{array}{l}35.98^{\star * *} \\
{[0.0000]}\end{array}$ & $\begin{array}{l}49.57^{* * *} \\
{[0.0000]}\end{array}$ & $\begin{array}{l}92.40^{* * *} \\
{[0.0000]}\end{array}$ & $\begin{array}{l}114.19^{* * *} \\
{[0.0000]}\end{array}$ & $\begin{array}{l}23.50^{* * *} \\
{[0.0000]}\end{array}$ \\
\hline RMSE & 0.0644 & 0.0846 & 0.0405 & 0.0595 & 0.0638 & 0.0926 \\
\hline $\begin{array}{l}\text { Cross } \\
\text { sections }\end{array}$ & 10 & 10 & 4 & 4 & 6 & 6 \\
\hline Periods & 25 & 25 & 25 & 25 & 25 & 25 \\
\hline Total Obs. & 250 & 250 & 100 & 100 & 150 & 150 \\
\hline
\end{tabular}

475 Values in brackets are standard errors, while those in parentheses are probabilities. ${ }^{* * *}$

476 and ** indicate significance at $1 \%$ and $5 \%$ critical levels respectively.

477

478 Table 8: Country-specific estimates for Middle-East countries from AMG

\begin{tabular}{|l|l|l|l|l|}
\hline & Iran & Iraq & Saudi Arabia & UAE \\
\hline ENG & $0.6170^{* *}$ & $0.8907^{* * *}$ & $0.8796^{* *}$ & $0.6071^{* * *}$ \\
\hline
\end{tabular}




\begin{tabular}{|l|l|l|l|l|}
\hline & $(0.2498)$ & $(0.0604)$ & $(0.4219)$ & $(0.2322)$ \\
\hline GDP & $-0.3307^{*}$ & 0.0382 & -0.0187 & 0.2227 \\
& $(0.1771)$ & $(0.0617)$ & $(0.3621)$ & $(0.1826)$ \\
\hline URB & $0.9989^{* * *}$ & $0.4304^{* * *}$ & $1.0076^{* * *}$ & $0.1839^{* * *}$ \\
& $(0.3761)$ & $(0.1068)$ & $(0.3147)$ & $(0.0647)$ \\
\hline Constant & $-18.3830^{* * *}$ & $-13.2822^{* * *}$ & $-22.7135^{* * *}$ & $-8.1576^{* * *}$ \\
& $(5.0183)$ & $(1.5290)$ & $(4.1853)$ & $(2.7762)$ \\
\hline
\end{tabular}

479 Values in parentheses are probabilities. ${ }^{* * *},{ }^{* *}$ and ${ }^{*}$ indicate significance at $1 \%, 5 \%$ and $480 \quad 10 \%$ critical levels respectively.

481

482 Table 9: Country-specific long-run estimates for non-Middle-East countries from 483 AMG

\begin{tabular}{|l|l|l|l|l|l|l|}
\hline & Algeria & Angola & Congo, Dem. & Gabon & Nigeria & Venezuela \\
\hline ENG & $0.8081^{* *}$ & $2.1841^{* * *}$ & $-0.7388^{* *}$ & $0.6332^{* *}$ & $1.0218^{* *}$ & $0.7016^{* *}$ \\
& $(0.3843)$ & $(0.4698)$ & $(0.3731)$ & $(0.2485)$ & $(0.5188)$ & $(0.3518)$ \\
\hline GDP & 0.2283 & 0.0802 & 0.1181 & 0.6752 & $-0.6128^{* * *}$ & $0.8464^{* * *}$ \\
& $(0.2101)$ & $(0.2018)$ & $(0.1373)$ & $(0.7934)$ & $(0.1397)$ & $(0.1861)$ \\
\hline URB & $0.9469^{* * *}$ & $0.8089^{* * *}$ & 0.0868 & $0.9872^{* * *}$ & $1.0772^{* * *}$ & $1.5211^{* * *}$ \\
& $(0.1976)$ & $(0.1018)$ & $(0.0997)$ & $(0.2765)$ & $(0.0763)$ & $(0.1387)$ \\
\hline Constant & $-23.1606^{* * *}$ & $-26.9124^{* * *}$ & -1.4385 & $-23.6923^{* *}$ & $-20.6835^{* * *}$ & $-37.6217^{* * *}$ \\
& $(4.9370)$ & $(2.4412)$ & $(1.3350)$ & $(9.8390)$ & $(2.1164)$ & $(2.1164)$ \\
\hline
\end{tabular}


484 Values in parentheses are probabilities. ${ }^{* *}$ and ${ }^{* *}$ indicate significance at $1 \%$ and $5 \%$ 485 critical levels respectively.

\section{Concluding remarks}

488 Our major objective in this study is to examine the role that energy consumption plays 489 in the environmental quality of the OPEC countries. Motivated by their highest share of 490 crude oil exports of the Middle-Eastern countries of the OPEC group, as well as their

491 huge share in per capital energy consumption and per capita ecological footprint, we 492 further partition the full sample into two sub-samples namely Middle-Eastern and non493 Middle-Eastern countries. The essence is to discover if such high level of per capita 494 energy use by the Middle-East countries will accordingly lead to high environmental 495 degradation compared to other countries, or otherwise. To do this, we collect annual 496 data for 10 OPEC countries over the period of 1990 to 2014. Putting certain features of 497 panel series, such as cross-sectional dependence and heterogeneity, into consideration, 498 we employ second generation estimation techniques that can conveniently handle these 499 inherent issues. Accordingly, we begin the estimation process by testing for the 500 presence of cross-section dependence among the panel members using a battery of 501 cross-sectional dependence tests. Upon ascertainment of strong interdependencies 502 among the series, our unit root tests which are consistent with the issue reveal that the 503 series are largely non-stationary across all the sub-samples, with the only exemption 504 being urban population. Consequent on this, the cointegration test suggests that long- 
505 run relationship exists among the variables, thus informing our preference for the 506 Augmented Mean Group that is able to account for all these aforementioned concerns.

507 We find that energy consumption significantly and positively impacts ecological 508 footprint across all the samples. However, the marginal contribution of energy 509 consumption in the Middle-Eastern countries that are apparently the highest exporters 510 of crude oil and highest per capita consumers of energy in the OPEC group is smaller 511 than that of the non-Middle-Eastern countries. Similarly, the established impact of the 512 degree of urbanization on ecological footprint is expectedly higher for the non-Middle513 Eastern countries due to their higher population. Economic growth seems not to matter 514 at all in impacting environmental quality in all cases. We further add precision to our 515 analysis by considering country-specific estimates of the AMG estimator. In the Middle516 East group, energy consumption has the greatest adverse effect on environmental

517 quality while UAE records the least. On the other hand, only the Democratic Republic 518 of Congo has their energy use reduce environmental degradation following the 519 coefficient of per capita energy consumption $(-0.7388 \%)$. However, the scenario is 520 particularly worse for Angola whose increasing energy consumption effect on 521 environmental degradation $(2.1841 \%)$ is more than double of the country (Nigeria) 522 ranking next to it $(1.0218 \%)$.

\section{6. Policy implications}

524 Our findings definitely have instructive policy suggestions for in a number of ways. The 525 increasing effect of energy consumption on environmental degradation in the OPEC 
526 countries is a clear indication of their energy intensity. Of equal importance is that due

527 to the huge deposits of non-renewable energy resources, especially crude oil in their 528 borders, the use of fossil fuels outpaces renewable energy consumption. The carbon 529 generated from the consumption of the fossil fuels is perhaps the major cause of the 530 huge environmental concerns. At the same time, it has no economic sense to strictly 531 suggest that attention should be shifted away from the consumption of fossil fuels due 532 to its immense contribution to the economic growth and development of these 533 countries. Hence, we recommend a proper energy reshuffling or energy mix between 534 the renewable energy and non-renewable energy sources. This will not only ensure an 535 enhanced environmental quality through mitigation of carbon release, but the 536 renewable energy sources have been regarded as the solution to challenges of future 537 energy security and unemployment (see Mu et al., 2018; Proenca and Fortes, 2020; and 538 Edenhofer et al., 2011). Additionally, the non-Middle-Eastern countries should ensure 539 improved energy use efficiency following their higher impact on environmental 540 degradation despite having lower average per capita energy consumption. The 541 governments of the countries can also introduce carbon cuts through placing limits on 542 the amount of carbon that can be emitted by the firms. The excess can then be traded. In 543 keeping with the carbon cuts policy, firms with excess carbon emissions can be 544 appropriately taxed.

545 Other policy focus relates to the demographic feature of the OPEC countries, 546 irrespective of the sub-samples they fall into. Having discovered the strong significance 
547 of the urban population in inducing environmental degradation, probably due to 548 increased demand or higher pressure on natural resources, the impact can yet be 549 favourable if the government introduces relevant urban plans that give rise to easy 550 access to efficient and clean technology.

\section{Declarations}

\section{A. Ethics approval and consent to participate}

\section{B. Consent for publication} All the co-authors have given their consents for publication.

\section{Availability of data and materials} The data are available upon reasonable request.

\section{Competing interests}

None of the authors have any competing interest.

\section{E. Funding}

Not applicable.

\section{F. Authors' contributions}

Oluwasegun B. Adekoya: Conceptualization, Methodology, Analysis, Discussion of results. Joshua K. Olabode: Writing, Data curation, Editing.

Not applicable

\section{References}


571 Al-Mulali, U. (2014). Investigating the impact of nuclear energy consumption on GDP 572 growth and $\mathrm{CO}_{2}$ emission: A panel analysis. Progress in Nuclear Energy 73, 172-178.

573 Al-Mulali, U., Saboori, B. and Ozturk, I. (2015a). Investigating the environmental 574 Kuznets curve hypothesis in Viet Nam. Energy Policy 76, 123-131.

575 Bayomi, N. and Fernandez, J. (2019). Towards sustainable energy trends in the Middle 576 East: A study of four major emitters. Energies 12, 1-20.

577 Breush, T. and Pagan, A. (1980). The Lagrange multiplier test and its applications to 578 model specification in Econometrics. Review of Economic Studies 47, 145-150.

579 Burret, H. T., Feld, P. L. and Kohler, E. A. (2014). Sustainability of public debt in 580 Germany- Historical considerations and time series evidence. Journal of Economics and 581 Statistics 233, 291-335.

582 Chandran, V. and Tang, C. F. (2013). The impacts of transport energy consumption, 583 foreign direct investment and income on $\mathrm{CO}_{2}$ emissions in ASEAN-5 economies. 584 Renewable \& Sustainable Energy Reviews 24, 445-453.

585 Destek, M. A., Ulucak, R. and Dogan, E. (2018). Analyzing the environmental Kuznets 586 curve for the EU countries: The role of ecological footprint. Environmental Science and 587 Pollution Research 25, 29387-29396.

588 Dogan, E., Taspinar, N. and Gokmenoglu, K. K. (2019). Determinants of ecological 589 footprint in MINT countries. Energy \& Environment 30, 1065-1086. 
590 Dong, K. Hochman, G., Zhang, Y. Q., Sun, R., Li, H. and Liao, H. (2018d). CO 2 591 emissions, economic and population growth, and renewable energy: Empirical evidence 592 across regions. Energy Economics 75, 180-192.

593 Dong, K., Sun, R. and Hockman, G. (2017a). Do natural gas and renewable energy 594 consumption lead to less $\mathrm{CO}_{2}$ emission? Empirical evidence from a panel of BRICS 595 countries. Energy 141, 1466-1478.

596 Dong, K., Sun, R., Hochman, G., Zeng, X., Li, H. and Jiang, H. (2017b). Impact of natural 597 gas consumption on $\mathrm{CO}_{2}$ emissions: Panel data evidence from China's provinces. 598 Journal of Cleaner Production 162, 400-410.

599 Dong, K., Sun, R., Li, H. and Liao, H. (2018a). Does natural gas consumption mitigate $600 \mathrm{CO}_{2}$ emissions? Testing the environmental Kuznets curve hypothesis for 14 Asia-Pacific 601 countries. Renewable \& Sustainable Energy Reviews. 94, 419-429.

602 Eberhardt, M. and Bond, S. (2009). Cross-section dependence in nonstationary panel 603 models: A novel estimator. MPRA Paper 17692, University Library of Munich, 604 Germany.

605 Edenhofer, O., Pichs-Madruga, R., Sokona, Y., Seyboth, K., Kadner, S., Zwickel, T., 606 Eickemeier, P., Hansen, G., Schlömer, S., von Stechow, C. (2011). Renewable Energy 607 Sources and Climate Change Mitigation: Special Report of the Intergovernmental Panel 608 on Climate Change. Cambridge University Press. 
609 Galli, A., Iha, K., Moreno-Pires, S., Mancini, M. S., Alves, A., Zokai, G., Lin, D., Murthy, 610 A. and Wackemagel, M. (2020). Assessing the ecological footprint and biocapacity of 611 Portuguese cities: Critical results for environmental awareness and local management.

612 Cities 96, 102442. https:// doi.org/10.1016/j.cities.2019.102442.

613 Imamoglu, H. (2018). Is the informal economic activity a determinant of environmental 614 quality? Environmental Science and Pollution Research 25, 29078-29088.

615 Kasman, A. and Duman, Y. S. (2015). CO2 emissions, economic growth, energy 616 consumption, trade and urbanization in new EU member and candidate countries: A 617 panel data analysis. Economic Modelling 44, 97-103.

618 Kassouri, Y. and Altintas, H. (2020). Human well-being versus ecological footprint in 619 MENA countries: A trade-off? Journal of Enviromental Management 263, 110405.

620 Khan, M. K., Khan, M. I. and Rehan, M. (2020). The relationship between energy 621 consumption, economic growth and carbon dioxide emissions in Pakistan. Financial 622 Innovation 6, https://doi.org/10.1186/s40854-019-0162-0.

623 Lee, C. C. and Chang, C. P. (2008). Energy consumption and economic growth in Asian 624 economies: A more comprehensive analysis using panel data. Resource and Energy 625 Economics 30, 50-65.

$626 \mathrm{Li}, \mathrm{K}$. and Lin, B. (2015). Impacts of urbanization and industrialization on energy 627 consumption $/ \mathrm{CO}_{2}$ emissions: Does the level of development matter? Renewable and 628 Sustainable Energy Reviews 52, 1107-1122. 
629 Mu, Y., Cal, W., Evans, S., Wang, C and Ronald-Holst, D. (2018). Employment impacts

630 of renewable energy policies in China: A decomposition analysis based on a CGE 631 modeling framework. Applied Energy 210, 256-26.

632 Nunan, F. (2015). Understanding poverty and the environment: Analytical frameworks 633 and approaches.

634 Omri, A. (2013). CO2 emissions, energy consumption and economic growth nexus in 635 MENA countries: Evidence from simultaneous equations models. Energy Economics 40, $636 \quad 657-664$.

637 Ozcan, B., Tzeremes, P. G. and Tzeremes, N. G. (2019). Energy consumption, economic 638 growth and environmental degradation in OECD countries. Economic Modelling 84, $639 \quad 203-213$.

640 Pesaran, M. H. (2004). General diagnostic tests for cross section dependence in panels. 641 Pap. Econ., Cambridge Work 0435. https:// doi.org/10.17863/CAM.5113

642 Pesaran, M. H. (2006). Estimation and inference in large heterogenous panels with a 643 multifactor error structure. Econometrica 74, 967-1012.

644 Pesaran, M. H. (2007). A simple panel unit root test in the presence of cross-section 645 dependence. Journal of Applied Econometrics 22, 265-312.

646 Pesaran, M. H., Ullah, A. and Yamagata, T. (2008). A bias-adjusted LM test of error 647 cross-section independence. The Econometrics Journal 11, 105-127. 
648 Proenca, S. and Fortes, P. (2020). The social face of renewables: Econometric analysis of 649 the relationship between renewables and employment. Energy Reports 6, 581-586.

650 Seven, U., Kilinc, D. and Coskun, Y. (2018). Does credit composition have asymmetric 651 effects on income inequality? New evidence from panel data. International Journal of 652 Financial Studies 6, 1-15.

653 Solarin, S. A. and Al-Mulali, U. (2018). Influence of foreign direct investment on 654 indicators of environmental degradation. Environmental Science and Pollution 655 Research 21, 1-5.

656 Tran, N. V., Tran, Q. V., Do, L. T. T., Dinh, L. H. and Do, H. T. T. (2019). Trade off 657 between environment, energy consumption and human development: Do levels of 658 economic development matter? Energy 173, 483-493.

659 Uddin, G. A., Salahuddin, M., Alam, K. and Gow, J. (2017). Ecological footprint and real 660 income: Panel data evidence from the 27 highest emitting countries. Ecological 661 Indicators 77, 166-175.

662 Ulucak, R. and Apergis, N. (2018). Does convergence really matter for the environment? 663 An application based on club convergence and on the ecological footprint concept for 664 the EU countries. Environmental Science and Policy 80, 21-27.

665 Vackar, D. (2012). Ecological footprint, environmental performance and biodiversity: A 666 cross-national comparison. Ecological Indicators 16, 40-46. 
667 Vanham, D., Leip, A., Galli, A., Kastner, T., Bruckner, M., Uwizeye, A., van Dijk, K., 668 Ercin, E., Dalin, C., Brandao, M., Bastianoni, S., Fang, K., Leach, A., Chapagain, A., Van 669 der Velde, M., Sala, S., Pant, R., Mancini, L., Monforti-Ferrario, F., Carmona-Garcia, G., 670 Marques, A., Weiss, F. and Hoekstra, A. Y. (2019). Environmental footprint family to 671 address local to planetary sustainability and deliver on the SDGs. Science of the Total 672 Environment 693, 133642. https://doi.org/10.1016/j.scitotenv.2019.133642.

673 Wackernagel, M. and Rees, W. (1996). Our ecological footprint: Reducing human impact 674 on the earth. Gabriola Island: New Society Publishers.

675 Wang, J. and Dong, K. (2019). What drives environmental degradation? Evidence from 67614 sub-Saharan African countries. Science of the Total Environment 656, 165-173.

677 Wang, Y., Chen, L. and Kubota, J. (2016). The relationship between urbanization, energy 678 use and carbon emissions: Evidence from a panel of Association of Southeast Asian 679 Nations (ASEAN) countries. Journal of Cleaner Production 112, 1368-1374.

680 Westerlund, J. (2007). Testing for error correction in panel data. Oxford Bulletin of 681 Economics and Statistics 69, 709-748.

682 York, R. (2007). Demographic trends and energy consumption in European Union 683 Nations, 1960-2025. Social Science Research 36, 855-872.

684 Zoundi, Z. (2017). $\mathrm{CO}_{2}$ emissions, renewable energy and the Environmental Kuznets 685 Curve: A panel cointegration approach. Renewable \& Sustainable Energy Reviews 72, $686 \quad 1067-1075$. 
Figures

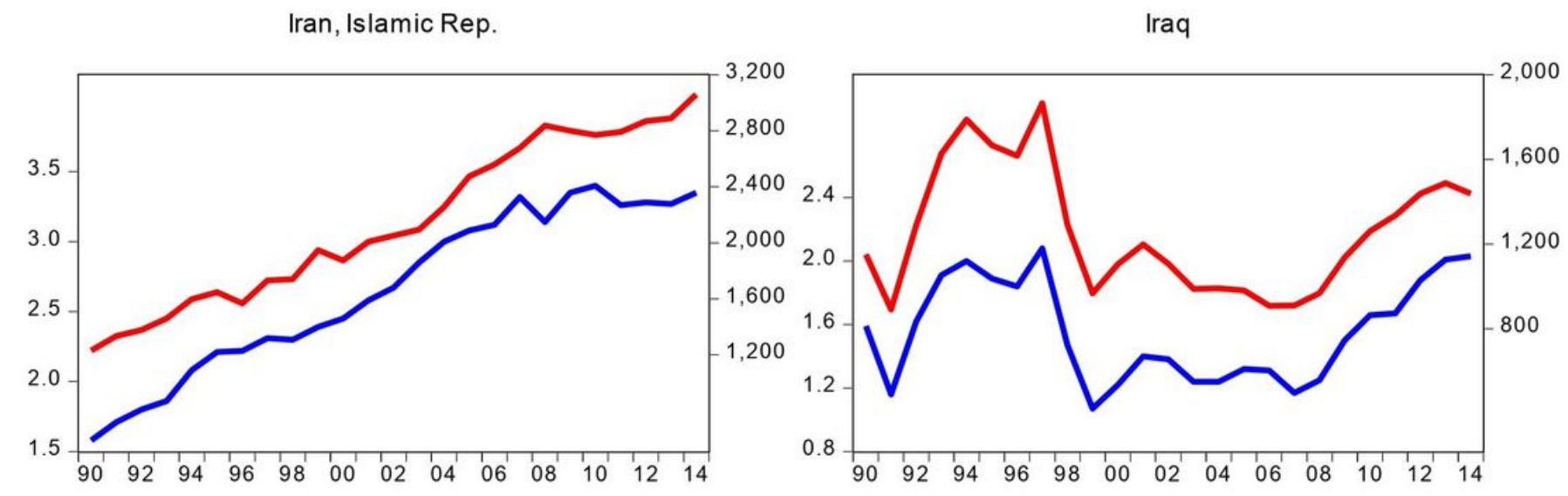

Saudi Arabia

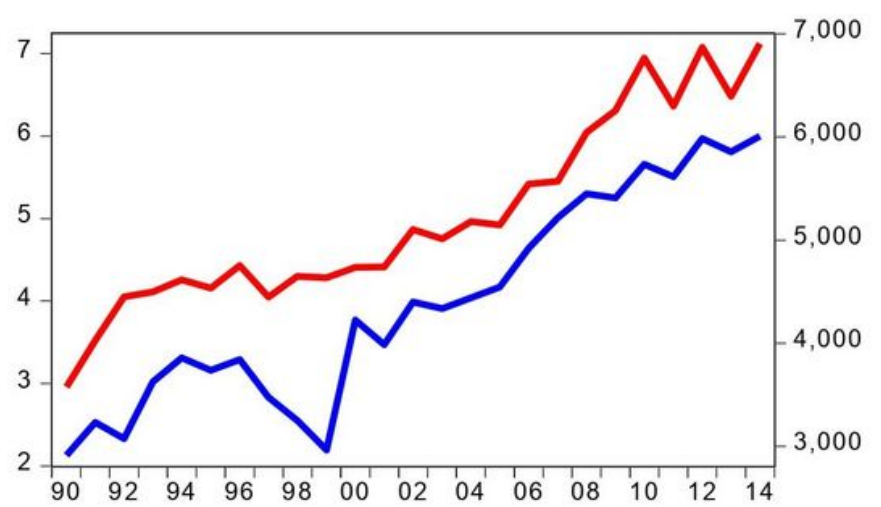

United Arab Emirates

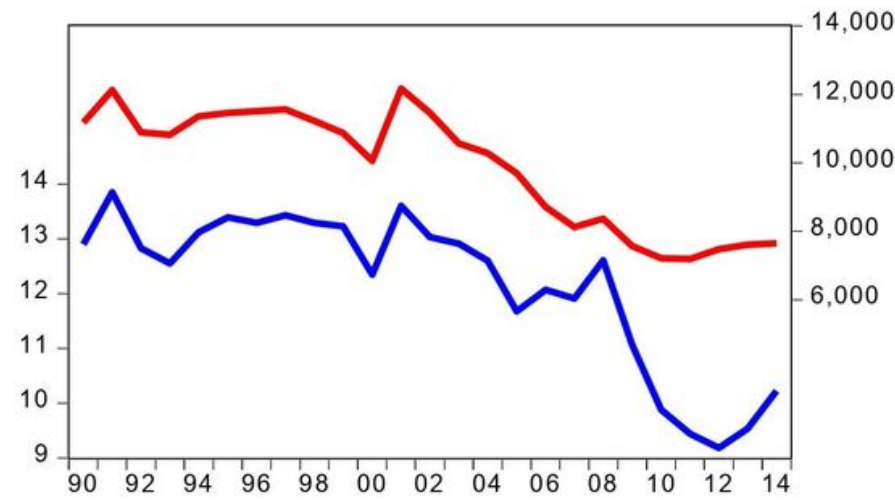

$$
\text { - EF - eng }
$$

Figure 1

Trends in ecological footprint and energy consumption in Middle-Eastern countries 
Algeria

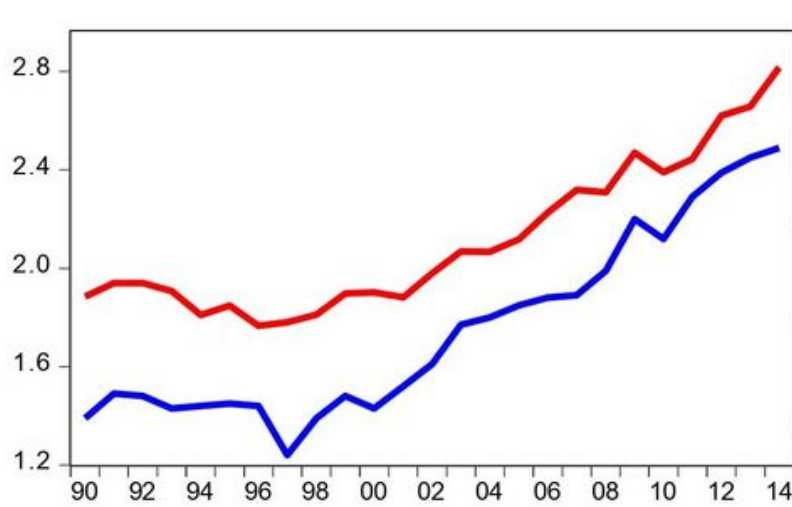

Congo, Dem. Rep.

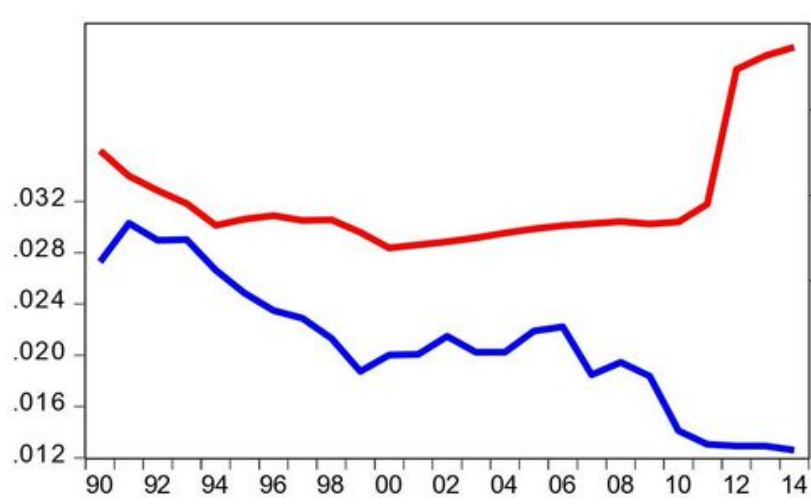

Nigeria

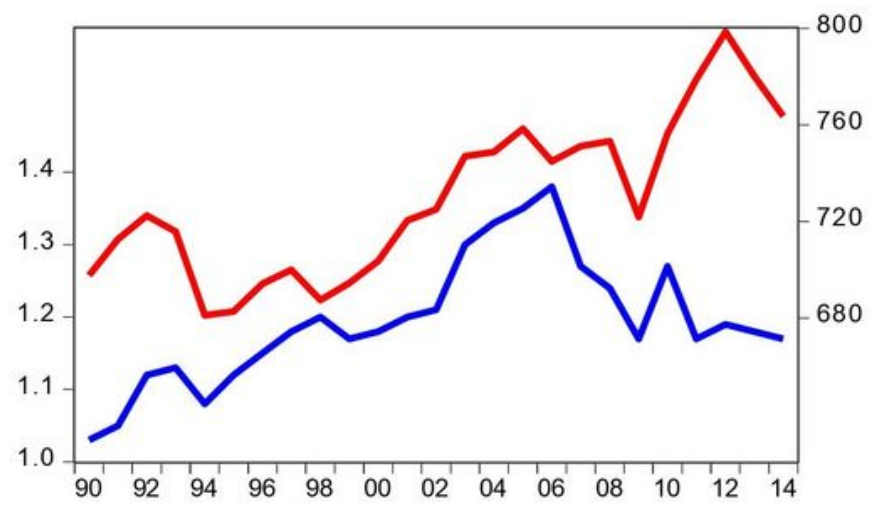

Angola

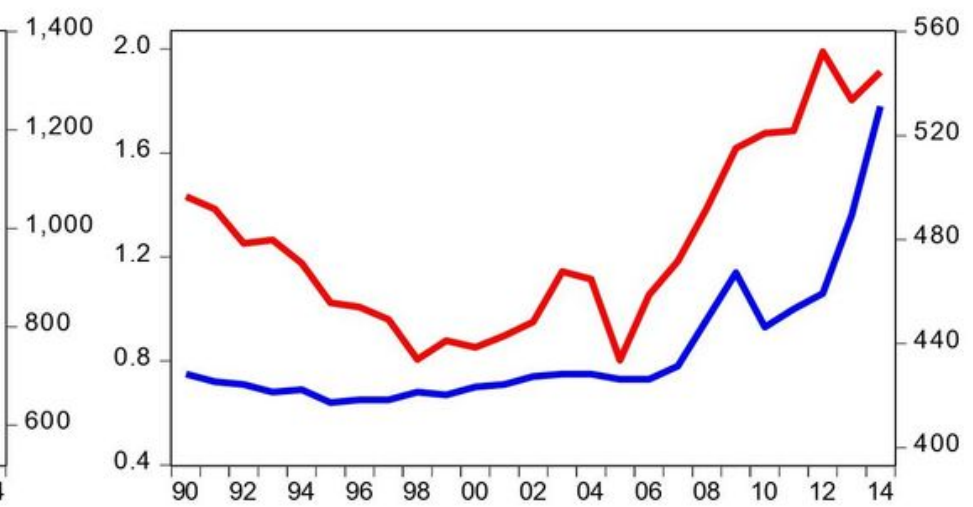

Gabon

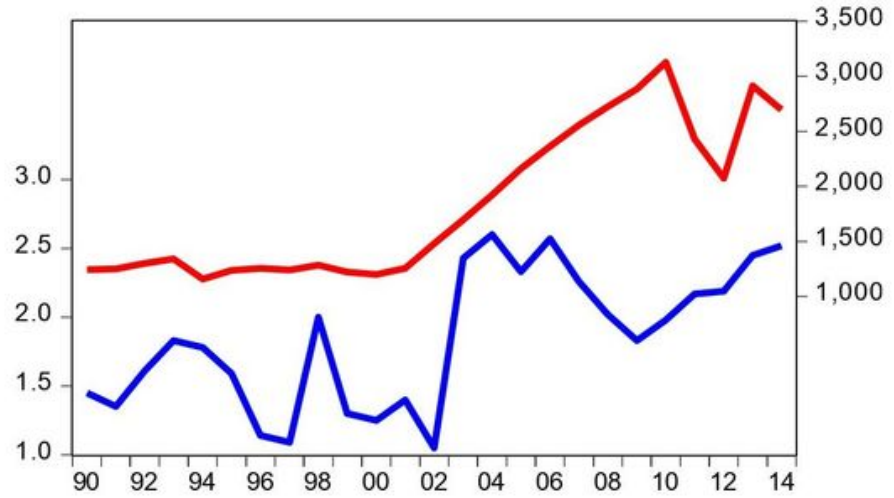

Venezuela, RB

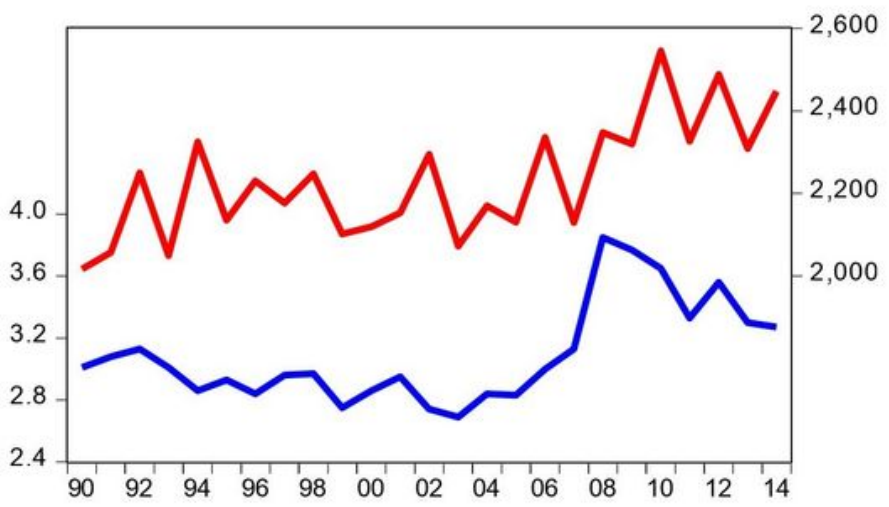

- EF — eng

Figure 2

Trends in ecological footprint and energy consumption in non-Middle-Eastern countries 